\title{
Comparative study on the extraction of natural dye by conventional magnetic stirring and ultrasound-assisted extraction techniques from carrot
}

\section{Chanda Bramhankar, Archana Khare, Pranali Nikam, Mehar Afroz Qureshi and Y.K. Naik}

See end of the Paper for authors' affiliation

Correspondence to :

Chanda Bramhankar Department of Dairy Chemistry, College of Dairy Science and Food Technology, Chhattisgarh Kamdhenu Vishwavidyalaya, Raipur (C.G.) India

Email : bramhankarchanda@ gmail.com
Abstract : In the food and dairy industry, most of the colouring agents used are artificial in nature which are reported to cause harmful effects when consumed in higher doses. Carotenoides is red orange colour pigment present in carrot and can be used as a natural dye in milk and milk products. Looking to the above fact as attempt was made for the extraction of Carotenoids by conventional magnetic stirring (MS) and ultrasound-assisted extraction techniques (UAE). A comparative study of extraction of Carotenoids from the carrot were systematically evaluated between MS and UAE. The optimum operating conditions to yield maximum Carotenoids from the carrot were fixed. The solvent used for extraction was ethanol. The power, frequency, temperature, time and agitation speed were $150 \mathrm{~W}, 40 \mathrm{kHz}, 50^{\circ} \mathrm{C}, 25$ minute and $100 \mathrm{rpm}$, respectively. It has been observed that Carotenoids yield was higher in UAE $(0.008 \%)$ as compared with MS $(0.006 \%)$.

- Key words : Carrot, Ultrasound-assisted extraction, Magnetic stirring, Carotenoids, Natural dye

- How to cite this paper : Bramhankar, Chanda, Khare, Archana, Nikam, Pranali, Qureshi, Mehar Afroz and Naik, Y.K. (2018). Comparative study on the extraction of natural dye by conventional magnetic stirring and ultrasound-assisted extraction techniques from carrot. Internat. J. Agric. Engg., 11(Sp. Issue) : 99-101, DOI: 10.15740/HAS/IJAE/11.Sp. Issue/99-101. 